\title{
Knowledge and Attitudes of Hospital Pharmacy Staff in Canada Regarding Medical Assistance in Dying (MAiD)
}

\author{
Adrienne Gallagher, Odette Gould, Michael LeBlanc, Leslie Manuel, and Diane Brideau-Laughlin
}

\begin{abstract}
Background: In February 2015, the Supreme Court of Canada ruled that it was unconstitutional to prohibit physicians from assisting in a patient's consensual death, thereby setting the groundwork for the legalization of medical assistance in dying (MAiD). Much of the research on this topic has focused on physicians, although other health care professionals will be involved in the process, including pharmacists, pharmacy technicians, and pharmacy assistants. In many provinces, the medications required for MAiD will be dispensed from hospital pharmacies, which will result in direct involvement of hospital pharmacy staff.

Objectives: The primary objective was to investigate the knowledge and attitudes of hospital pharmacy staff in Canada regarding MAiD. The secondary objective was to determine the factors that might influence those opinions.

Methods: A 34-question web-based survey was available for 6 weeks during early 2017 to hospital pharmacy staff throughout Canada. For most questions, responses were based on a 5-point Likert scale, ranging from "strongly agree" to "strongly disagree". Descriptive and inferential statistics were used to analyze the data.

Results: A total of 1040 valid survey responses were received: 607 from pharmacists, 273 from pharmacy technicians, and 160 from pharmacy assistants. Most respondents were supportive of MAiD; however, nearly all respondents (99\% [601/607] of pharmacists, 73\% [315/431] of technicians and assistants]) reported lacking comprehensive education on the topic. Despite high levels of overall support, pharmacists tended to be less supportive of MAiD than pharmacy technicians or assistants. Factors that influenced opinions included strong religious beliefs, region, and knowledge of provincial and federal legislation.
\end{abstract}

Conclusions: The majority of respondents, particularly technicians and assistants, were supportive of MAiD, but most respondents lacked education about the topic.

Keywords: medical assistance in dying, assisted suicide, hospital pharmacists, pharmacy technicians, pharmacy assistants

Can J Hosp Pharm. 2018;72(1):16-26

\section{RÉSUMÉ}

Contexte : En février 2015, la Cour suprême du Canada a statué qu'il était inconstitutionnel d'interdire aux médecins d'aider les patients à mourir par consentement, ce qui a jeté les bases de la légalisation de l'aide médicale à mourir (AMAM). Une grande partie de la recherche sur le sujet était axée sur les médecins, malgré le fait que d'autres professionnels de la santé seront appelés à participer au processus, notamment les pharmaciens, les techniciens en pharmacie et les aides-pharmaciens. Dans bien des provinces, les médicaments nécessaires à l'AMAM proviendront des pharmacies hospitalières, ce qui résultera en la participation directe du personnel de pharmacie hospitalière.

Objectifs : L'objectif principal visait à examiner les connaissances et l'attitude du personnel de pharmacie hospitalière au Canada relativement à l'AMAM. L'objectif secondaire était de découvrir les facteurs pouvant influencer les avis du personnel sur le sujet.

Méthodes : Pendant six semaines, au début de 2017, un sondage en ligne de 34 questions était à la disposition du personnel de pharmacie hospitalière de partout au Canada. Inspirés de l'échelle de Likert à cinq points, les choix de réponse à la plupart des questions s'étendaient de « fortement d'accord » à " fortement en désaccord ». Des statistiques descriptives et par inférence ont servi à analyser les données.

Résultats : Des 1040 réponses valables, 607 provenaient de pharmaciens, 273 de techniciens en pharmacie et 160 d'aides-pharmaciens. La plupart des répondants étaient en faveur de l'AMAM. Cependant, près de l'ensemble des répondants (99\% [601/607] des pharmaciens et $73 \%$ [315/431] des techniciens et des aides) ont signalé ne pas posséder une connaissance suffisante du sujet. Malgré le degré élevé de soutien apporté par l'ensemble des personnes interrogées, l'appui des pharmaciens à l'AMAM tendait à être plus faible que celui des techniciens en pharmacie ou des aides-pharmaciens. Parmi les facteurs propres à influencer les avis des répondants, on trouvait les croyances religieuses fortes, la provenance géographique et la connaissance des lois provinciales et fédérales.

Conclusions : La majorité des répondants, particulièrement les techniciens et les aides, était en faveur de l'AMAM, mais la plupart des répondants ne possédaient pas une connaissance suffisante du sujet.

Mots clés : aide médicale à mourir, suicide assisté, pharmaciens d'hôpitaux, techniciens en pharmacie, aides-pharmaciens 
This single copy is for your personal, non-commercial use only.

For permission to reprint multiple copies or to order presentation-ready copies for distribution, contact CJHP at publications@cshp.ca

\section{INTRODUCTION}

$\mathrm{O}^{\prime}$

February 6, 2015, the Supreme Court of Canada released its judgment in the case of Carter v. Canada (Attorney General), specifying that any person who has a "grievous and irremediable medical condition (including an illness, disease, or disability)" ${ }^{1}$ has the right to pursue medical assistance in dying (MAiD). Those requesting MAiD must be competent adults who have clearly consented to the termination of life, and whose condition must cause enduring, intolerable suffering. ${ }^{1}$

Switzerland was the first country to decriminalize assistance in suicide (in 1942). ${ }^{2}$ Euthanasia or physician-assisted suicide is currently also legal in the Netherlands, Belgium, Luxembourg, Colombia, and several US states (Oregon, Washington, Montana, Vermont, and California). ${ }^{3}$ Euthanasia involves a person (usually a physician) actively and intentionally terminating a patient's life by some medical means such as an injection ${ }^{4}$ and has been legal in the province of Quebec since 2014. ${ }^{5}$ Physician-assisted suicide occurs when physicians prescribe lethal drugs at a patient's request, with the drugs being self-administered. ${ }^{3}$ MAiD in Canada encompasses both euthanasia and physician-assisted suicide and is carried out at the request of the patient, after strict criteria have been met (e.g., informed consent, intolerable suffering, and irremediable medical condition). It is up to the patient, the patient's family and/or caregivers, and the patient's health care providers to decide on the best option.

The debate about MAiD almost always focuses on the patient and the physician, ${ }^{6,7}$ and little attention has been paid to the perspectives and experiences of other health care professionals who may be actively involved in the process. Pharmacists and pharmacy technicians/assistants will likely be dispensing prescriptions for use in MAiD, with pharmacists also counselling patients and families about these prescriptions. ${ }^{7}$ Moreover, in many jurisdictions (including the Northwest Territories, the Yukon, and New Brunswick), the medications required for MAiD are provided by hospital pharmacies, whether the medications are to be administered at a hospital or in the home. ${ }^{8}$ The medications involved may vary but usually include a benzodiazepine, a local anesthetic, a coma-inducing agent, and a neuromuscular blocker. ${ }^{9}$ Given expansion of the role of pharmacists from purely dispensing products to medication counselling and accepting responsibilities for the outcome of treatment with medications, the issue of MAiD is particularly salient for the profession of pharmacy. ${ }^{6,10}$

Several previous pharmacist surveys regarding MAiD were identified., ${ }^{7,11-17}$ Four studies considered hospital pharmacists, ${ }^{8,11,15,16}$ and only 2 included pharmacy technicians or assistants. ${ }^{8,16}$ Lau and others ${ }^{15}$ distributed one survey to community pharmacists and a different survey to hospital pharmacists. The survey intended for community pharmacists focused on attitudes and beliefs, whereas the survey distributed to hospital pharmacists had no questions regarding personal opinions, and instead was intended to investigate the presence of hospital guidelines for MAiD.
Hackett and Francis ${ }^{11}$ distributed a survey to both hospital and community pharmacists in the United Kingdom, and found that community pharmacists were significantly less likely than hospital pharmacists to want to know the intended purpose of medications for assisted dying. (It should be noted that MAiD was illegal in Britain at that time, and remains so today.) These researchers hypothesized that the opinions of hospital pharmacists might differ from those of community pharmacists because hospital pharmacists are likely to have greater access to patient information (e.g., diagnosis, age, comorbidities, medical history) than community pharmacists. ${ }^{11}$ Additionally, community pharmacists are less likely than hospital pharmacists to have frequent and direct contact with the prescriber. ${ }^{11}$ Hanlon and others $^{7}$ also speculated that hospital pharmacists are more likely to have contact with terminally ill patients and that those experiences may have an effect on their opinions on the topic of MAiD.

A survey by the Canadian Pharmacists Association (CPhA) included both community and hospital pharmacists, as well as technicians. ${ }^{16}$ However, most respondents (more than $70 \%$ ) worked in the community, and only $1 \%$ of respondents were pharmacy technicians. That survey focused on freedom of conscience and the legislation, rather than the beliefs and attitudes of pharmacy professionals. A more recent survey, by Murphy and others, ${ }^{17}$ involved community pharmacists' attitudes toward suicide and their professional experiences with people at risk of suicide. The recently published study by Verweel and others ${ }^{8}$ compared legislation across Canada and also surveyed members of the Ontario Pharmacists Association (i.e., pharmacists, technicians, and students). It identified a variety of concerns, including issues related to dispensing medications and answering inquiries about MAiD. ${ }^{8}$

In light of the relative lack of information about the views of Canadian hospital pharmacy staff regarding MAiD, the purpose of the present study was to determine the current knowledge and attitudes of hospital pharmacy staff in Canada regarding MAiD and to identify specific factors affecting these attitudes. We hypothesized that pharmacy staff reporting that their religious beliefs influenced their professional work would be less supportive of MAiD $\mathrm{M}^{7,11,12,15}$ and that pharmacy staff who had frequent interactions with terminally ill patients and/or had worked in palliative care or oncology would be more supportive of MAiD. ${ }^{12}$ On the basis of previous results, we expected that a majority of those surveyed would report needing more training in the area of MAiD, particularly in terms of what drugs should be used and how to counsel patients and their families. ${ }^{8,16} \mathrm{We}$ also compared responses provided by pharmacists with responses provided by a combined group of pharmacy technicians and assistants, to examine differences between these 2 groups.

\section{METHODS}

An online software tool, FluidSurveys, was used to distribute a 34-question web-based anonymous survey to hospital pharmacy 
staff throughout Canada. The survey was available in both French and English for 6 weeks between January and March 2017. The survey questions were developed by the research team, with some questions being adapted (with permission) from previous surveys. ${ }^{7,12,18}$ During development of the survey, a focus group of pharmacists and pharmacy technicians/assistants at the authors' site was used to assess the clarity of the questions and the face validity of the instrument.

Preliminary questions addressed demographic status and work experiences (e.g., amount of time spent in direct patient care and amount of interaction with patients with end-stage disease or disability). In the main section of the survey, the first group of 4 items (concerning MAiD education) addressed the amount of MAiD-related education that the respondent had received, with answers ranging from "nothing at all" to "comprehensive education". The second group of 4 items (concerning values) measured level of agreement with the general notion of MAiD, and the third set of 5 items (concerning reluctance) asked about personal willingness to carry out tasks related to MAiD. The questions for these groups of items are available in Box 1. For the latter 2 sets of items, Likert scales ranging from 1 (strongly agree) to 5 (strongly disagree) were used, such that a higher score indicated opposition to MAiD. Next, respondents were asked to rate the eligibility criteria for MAiD ( 8 items) laid out by the government of $\mathrm{Canada}^{19}$ on a scale ranging from 1 (not important) to 5 (very important). The fifth set of 3 questions addressed self-reported level of knowledge about federal, provincial, and institutional legislation and guidelines regarding MAiD. Lastly, respondents were asked how influential their religious beliefs were on their work in relation to MAiD (on a scale ranging from 1 [not important at all] to 7 [absolutely essential]), with the option of answering "not applicable". In a second question in this part of the survey, respondents were asked what guidance their religious affiliation provided regarding $\mathrm{MAiD}$, on a scale ranging from 1 (permits MAiD) to 7 (does not permit MAiD).

\section{Participants}

An invitation to participate in the survey was distributed to hospital pharmacies across Canada through provincial and territorial pharmacy regulatory bodies, pharmacists' associations, pharmacy directors, the Canadian Society of Hospital Pharmacists, and the Association des pharmaciens des établissements de santé du Quebec. One reminder email was sent to all parties at the halfway point of data collection.

The research protocol was reviewed and approved by 2 research ethics board (from the home institutions of the coauthors) in December 2016. Participants read a cover letter describing the study, and indicated informed consent by completing the anonymous survey. Respondents who identified their primary area of practice as community pharmacy or some other nonhospital setting were excluded from the study.

\section{Box 1. Statements Regarding Medical Assistance in Dying (MAiD) Included in a Survey of Hospital Pharmacy Staff*}

\section{Values}

In my opinion, a dying patient has the right to end his or her life. In my opinion, a patient has the right to end his or her life with the assistance of medical professionals.

In my opinion, it is appropriate for MAiD to be accomplished through the use of prescription medications.

If a pharmacist refuses to be involved in MAiD, it is his or her responsibility to refer the patient/other health care professional to a pharmacist willing to be involved in the process.

\section{Reluctance}

I am willing to participate in the procurement, preparation, and dispensing of medications for use in MAiD.

I would knowingly participate in the dispensing of a prescription for use in MAiD.

It is appropriate for a pharmacist or pharmacy technician/assistant to refuse to dispense a prescription if they know it will be used for MAiD. $†$

As part of the health care team, I am willing to participate in deciding if a patient meets eligibility criteria for MAiD. $\neq$ I am willing to counsel patients and their family on medications prescribed for use in MAiD. $\neq$

* Responses were based on a Likert scale ranging from 1 (strongly agree) to 5 (strongly disagree), where a higher score indicated opposition to MAiD.

†This item was reverse-coded.

¥Question that appeared only on the survey for pharmacists because this aspect is beyond the scope of practice of technicians and assistants.

\section{Statistical Analyses}

Descriptive statistics, including means and standard deviations, were used to describe the respondents' demographic information. For questions with Likert-scale responses, a 1-sample $t$ test was used to determine whether the group mean was significantly different from the midpoint on the scale. Inferential statistics ( $t$ tests and analysis of variance) were used to compare pharmacists and a combined group of pharmacy technicians and pharmacy assistants (referred to hereafter as "technicians/ assistants") in terms of their knowledge and attitudes regarding MAiD. When multiple $t$ tests were used, a Bonferroni correction was applied to control for family-wise $\alpha$ inflation. Namely, the critical $p$ value used to establish statistical significance was calculated as 0.05 divided by the number of items in each section of the survey. Parallel nonparametric tests (Wilcoxon and MannWhitney $U$ tests) were carried out when normality assumptions were not met, but all results remained the same, and therefore the results of parametric inferential tests are reported. Means, standard deviations (SDs), medians, and interquartile ranges (IQRs) are reported where relevant. Pearson and point-biserial correlations were used to investigate the relationships between pharmacist and technician/assistant characteristics and responses to questions 
about values regarding MAiD and reluctance to carry out MAiD. Parallel nonparametric Spearman correlations were calculated, and differences in results obtained are noted. All analyses were carried out using IBM-SPSS version 22.0 software (IBM, Armonk, New York).

\section{RESULTS}

A total of 1040 valid survey responses were received (Figure 1). The respondents consisted of 607 pharmacists, 273 pharmacy technicians, and 160 pharmacy assistants. It was not possible to determine the response rate in relation to the number of pharmacists and technicians/assistants working in Canadian hospitals. Currently, the Alberta College of Pharmacists does not provide detailed statistics to the National Association of Pharmacy Regulatory Authorities, submitting only the total number of licensed pharmacists and technicians. It was therefore not possible to determine the total number of pharmacists and technicians practising in the hospital setting in Canada. Pharmacy assistants are not regulated, and therefore the total number of practising assistants was unavailable. ${ }^{20}$ Given the similarities in many of the functions performed in hospital pharmacy practice by technicians and assistants, the results of their responses were combined for further analysis. The responses represented all 10 provinces and 1 territory. Demographic information is presented in Table 1.

In terms of professional experience, pharmacists reported spending more time in direct patient care than did technicians/ assistants $(t(1028.83)=17.22, p<0.001)$. Whereas the modal response for pharmacists was $75 \%-100 \%$ of time spent in direct patient care (mean 2.8 [SD 1.2] on 4-point scale), the technicians/ assistants had a modal response of $0 \%-25 \%$ of the time (mean 1.5 [SD 0.9] on 4-point scale). Pharmacists also reported having had more interactions with patients with end-stage disease $(t(1024.10)=20.33, p<0.001)$. Whereas the modal response for pharmacists ( $n=195 / 606$ or 32\% of the sample) was "occasionally" (mean 3.0 [SD 1.3] on 5-point scale), the modal response for technicians/assistants $(n=300 / 429$ or $70 \%$ of the sample) was "very rarely" (mean 4.4 [SD 1.0] on 5-point scale).

\section{MAiD Education}

The majority of pharmacists reported having received little to no education regarding MAiD during their formal pharmacy education $(601 / 607,99 \%)$ or through continuing education (453/607, 75\%). Similarly, the majority of respondents in the technician/assistant group reported having received little to no MAiD education during their formal pharmacy training $(315 / 431,73 \%)$ or continuing education $(366 / 422,87 \%)$. Whereas 28\% ( $n=171 / 606)$ of pharmacists reported seeking out self-directed learning on the topic, only $17 \%(n=74 / 423)$ of technicians/assistants had done so. When asked where education on MAiD should occur, the most frequent response from pharmacists $(376 / 604,62 \%)$ was during the entry-to-practice degree, and the most frequent response for technicians/assistants (215/431, 50\%) was through formal continuing education. One-sample $t$ tests showed that, for both groups of respondents,

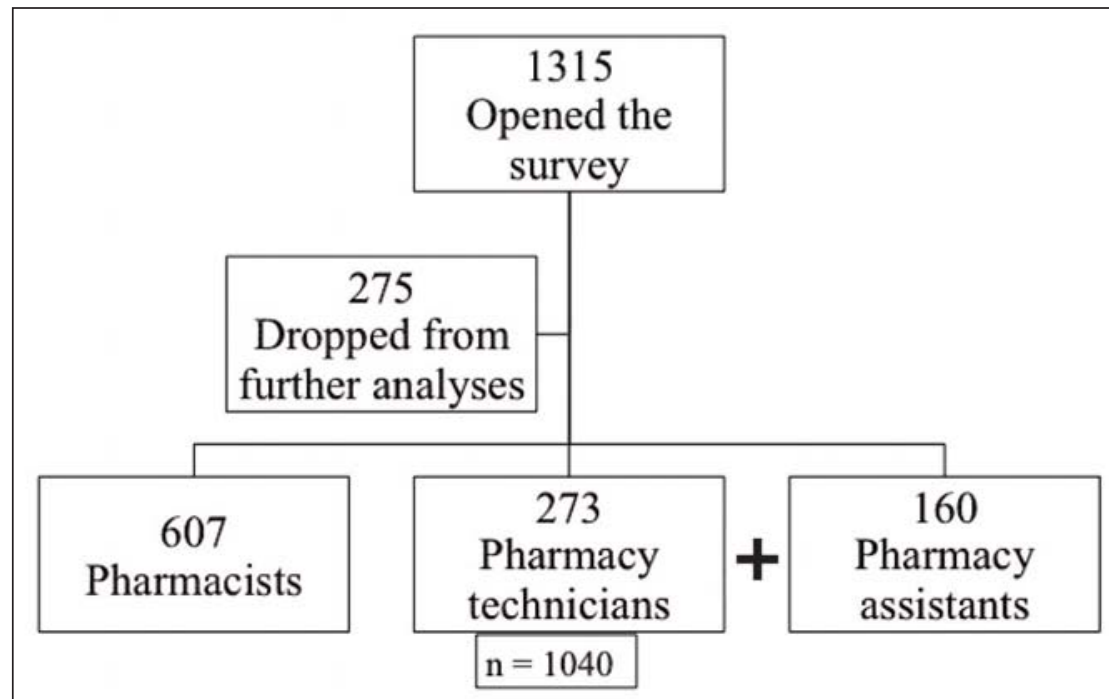

Figure 1. Flow chart for responses to an electronic survey concerning knowledge and attitudes of hospital pharmacy staff members regarding medical assistance in dying. Data for respondents who did not complete any questions, who did not complete the majority of questions, or were ineligible because they worked in community pharmacy (totalling 275) were omitted from further analysis. 


\section{Table 1. Demographic Characteristics of Hospital Pharmacy Respondents to a Survey Regarding Medical Assistance in Dying}

\begin{tabular}{|c|c|c|c|}
\hline \multirow[b]{2}{*}{ Characteristic } & \multicolumn{2}{|c|}{ No. (\%) of Respondents* } & \multirow[b]{2}{*}{$p$ Value } \\
\hline & $\begin{array}{l}\text { Pharmacists } \\
(n=607)\end{array}$ & $\begin{array}{l}\text { Technicians/ } \\
\text { Assistants } \\
(n=433)\end{array}$ & \\
\hline$\overline{\text { Sex }}$ & & & $<0.001 \ddagger$ \\
\hline Male & $155(26)$ & $26(6)$ & \\
\hline Female & $452(74)$ & $407(94)$ & \\
\hline Age (years) & $n=589$ & $n=422$ & \\
\hline Mean \pm SD & $39.66 \pm 10.63$ & $38.77 \pm 10.45$ & $0.19+$ \\
\hline Time in practice (years) & $n=601$ & $n=431$ & \\
\hline Mean \pm SD & $15.33 \pm 11.01$ & $14.41 \pm 9.51$ & $0.15+$ \\
\hline Education & $n=607$ & $n=433$ & - \\
\hline Bachelor of Pharmacy & $515(85)$ & NA & \\
\hline CCAP-accredited technician course & NA & $236(55)$ & \\
\hline Position & $n=605$ & $n=433$ & - \\
\hline Staff pharmacist & $467(77)$ & NA & \\
\hline Product preparation/dispensary & NA & $266(61)$ & \\
\hline Geographic location & $n=607$ & $n=433$ & $<0.001 \neq$ \\
\hline Alberta, British Columbia, Yukon & $227(37)$ & $215(50)$ & \\
\hline Saskatchewan, Manitoba & $119(20)$ & $50(12)$ & \\
\hline Ontario, Quebec & $120(20)$ & $75(17)$ & \\
\hline Atlantic provinces & $141(23)$ & $93(21)$ & \\
\hline Time spent in direct patient care & $n=606$ & $n=432$ & $<0.001 \neq$ \\
\hline$<50 \%$ & $264(44)$ & $367(85)$ & \\
\hline$\geq 50 \%$ & $342(56)$ & $65(15)$ & \\
\hline No. of beds in workplace & $n=605$ & $n=432$ & $0.01 \ddagger$ \\
\hline$\leq 200$ & $172(28)$ & $147(34)$ & \\
\hline$>200$ & $433(72)$ & $285(66)$ & \\
\hline Current practice area & $n=603$ & $n=431$ & - \\
\hline Oncology/hematology & $54(9)$ & $33(8)$ & \\
\hline Palliative care & $11(2)$ & $2(<1)$ & \\
\hline Other & $538(89)$ & $396(92)$ & \\
\hline Previous practice area & $n=607$ & $n=433$ & - \\
\hline Oncology/hematology & $114(19)$ & $72(17)$ & \\
\hline Palliative care & $76(12)$ & $19(4)$ & \\
\hline $\begin{array}{l}\text { No previous practice in oncology/ } \\
\text { hematology or palliative care }\end{array}$ & $417(69)$ & $342(79)$ & \\
\hline $\begin{array}{l}\text { Institutional policy } \\
\text { permitting MAiD }\end{array}$ & $\begin{array}{l}n=595 \\
460(77)\end{array}$ & $\begin{array}{l}n=423 \\
266(63)\end{array}$ & - \\
\hline
\end{tabular}

CCAP = Canadian Council for Accreditation of Pharmacy Programs,

$\mathrm{MAiD}=$ medical assistance in dying, $\mathrm{NA}=$ not applicable, $\mathrm{SD}=$ standard deviation

*Except when indicated otherwise.

tBy $t$ test.

$\neq B y \chi^{2}$ test.

the average ratings for MAiD education were significantly lower than the midpoint of the scale, which implied that respondents felt they did not have much education on the topic.

\section{Values}

Both groups were very supportive of MAiD in terms of values (Figure 2). One-sample $t$ tests showed that means were significantly different from the neutral response on the scale, in the direction indicating that respondents were supportive of MAiD. However, the pharmacist and technician/assistant groups differed significantly on several questions regarding their attitudes toward MAiD. The pharmacists were significantly more likely to disagree with the notion that patients have the right to end their own life $(t(1038)=4.31, p<0.001)$, the belief that patients have the right to end their life with the assistance of medical professionals $(t(1018.99)=5.46, p<0.001)$, and the belief that it is appropriate for MAiD to be accomplished through the use of prescription medications $(t(1038)=4.26, p<0.001)$. Pharmacists and technicians/assistants responded similarly when asked whether a pharmacy provider who refuses to be involved in MAiD is responsible for referring the patient to another professional 


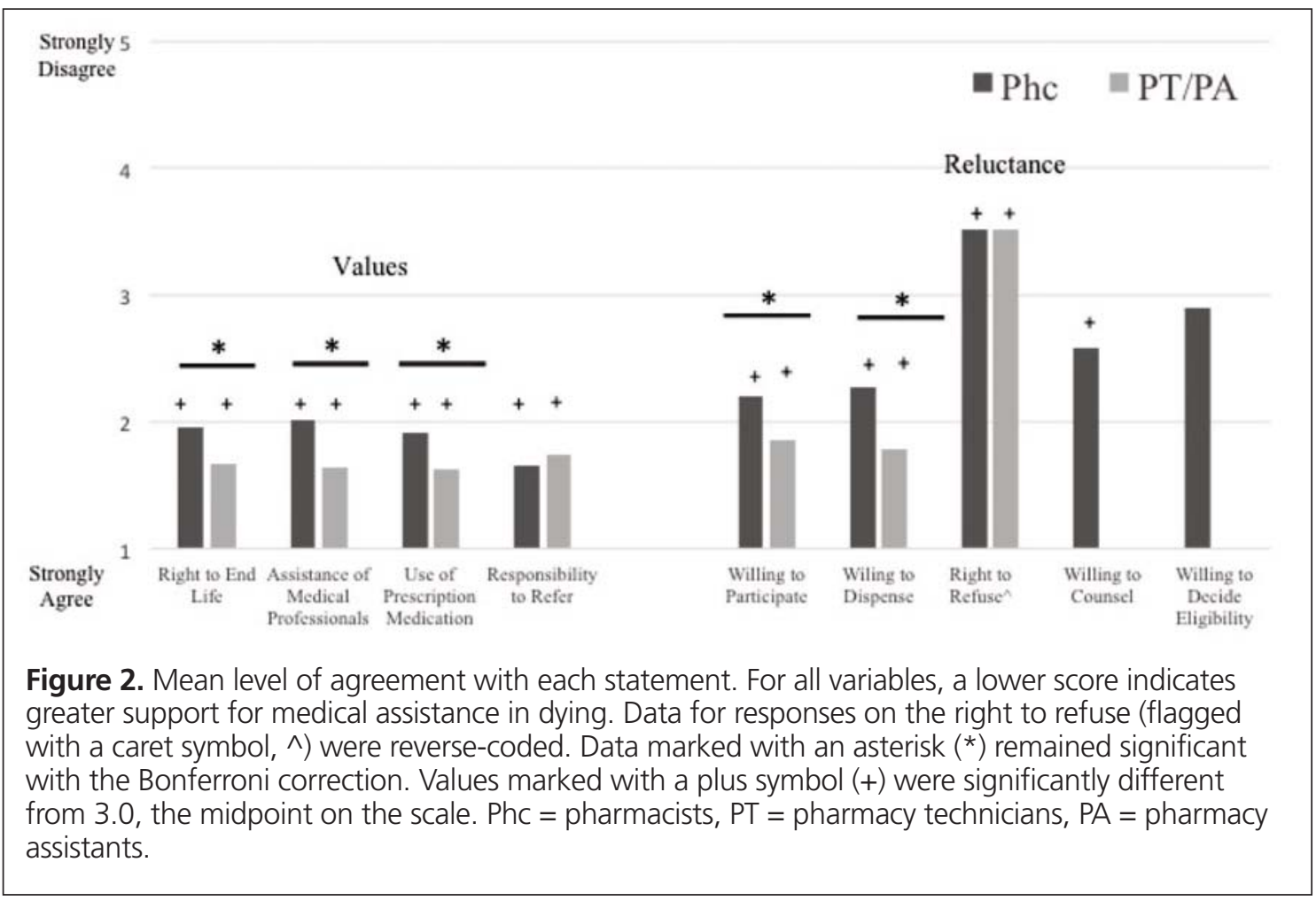

willing to be involved in the process. Comparisons between pharmacists and technicians/assistants in terms of levels of agreement with each value statement are presented in Table 2.

\section{Reluctance}

Overall, both groups were very supportive of MAiD in terms of factors related to reluctance (Figure 2). For both groups, most average responses were significantly different from the midpoint of the scale (in the direction showing support for MAiD), as indicated by 1 -sample $t$ tests. Respondents were asked to rate their own personal willingness to provide MAiD services. Relative to technicians/assistants, pharmacists were less willing to knowingly participate in dispensing a prescription for use in MAiD $(t(105.64)=4.50, p<0.001)$ and less willing to participate in the

Table 2. Responses across Questionnaire Items*

\begin{tabular}{|c|c|c|c|c|}
\hline \multirow[b]{2}{*}{ Item } & \multicolumn{2}{|c|}{$\begin{array}{l}\text { Professional Group; } \\
\text { No. (\%) Agreeingt }\end{array}$} & \multicolumn{2}{|c|}{$\begin{array}{l}\text { Professional Group; } \\
\text { No. (\%) Disagreeing } \neq\end{array}$} \\
\hline & $\begin{array}{l}\text { Pharmacists } \\
(n=607)\end{array}$ & $\begin{array}{c}\text { Technicians/ } \\
\text { Assistants } \\
(n=433)\end{array}$ & $\begin{array}{l}\text { Pharmacists } \\
(n=607)\end{array}$ & $\begin{array}{c}\text { Technicians/ } \\
\text { Assistants } \\
(\mathrm{n}=433)\end{array}$ \\
\hline \multicolumn{5}{|l|}{ Values } \\
\hline Right to end life & $474(78)$ & $364(84)$ & $68(11)$ & $25(6)$ \\
\hline Assistance of medical professionals & $471(78)$ & $370(85)$ & $83(14)$ & $26(6)$ \\
\hline $\begin{array}{l}\text { Use of prescription medication } \\
\text { for MAiD }\end{array}$ & $496(82)$ & $368(85)$ & $78(13)$ & $24(6)$ \\
\hline Responsibility to refer & $537(88)$ & $360(83)$ & $48(8)$ & $39(9)$ \\
\hline \multicolumn{5}{|l|}{ Reluctance } \\
\hline Willing to participate & $437(72)$ & $345(80)$ & $119(20)$ & $47(11)$ \\
\hline Willing to dispense & $426(70)$ & $345(80)$ & $121(20)$ & $38(9)$ \\
\hline Right to refuse & $360(59)$ & $243(56)$ & $146(24)$ & $112(26)$ \\
\hline Willing to counsel§ & $353(58)$ & NA & $155(26)$ & NA \\
\hline Willing to decide eligibility§ & $273(45)$ & NA & $211(35)$ & NA \\
\hline
\end{tabular}

$\mathrm{NA}=$ not applicable.

*Respondents used a 5-point Likert scale; data for the neutral response (3) are not reported in this table. tCombined responses of 1 (strongly agree) and 2 (agree).

¥Combined responses of 5 (strongly disagree) and 4 (disagree).

$\S$ Responses were solicited from pharmacists only, because counselling and deciding eligibility are beyond the scope of practice of technicians and assistants. 
procurement, preparation, and dispensing of medications for use in MAiD $(t(1017.21)=6.38, p<0.001)$. The groups did not differ significantly in terms of their views of whether it is appropriate for a pharmacist or technician/assistant to refuse to dispense a prescription if it is known that the medication will be used for $\operatorname{MAiD}(t(871.55)=0.01, p=0.99)$. Respondents were asked whether they wished to be told if a prescription they were dispensing would be used for MAiD: $87 \%(n=531 / 607)$ of pharmacists and 54\% $(n=233 / 430)$ of technicians/assistants said yes $\left(\chi^{2}(2, N=1037)=144.16, p<0.001\right)$. When asked if they had ever dispensed a prescription for MAiD after it became legal, $18 \%(n=107)$ of pharmacists were sure they had, and $78 \%$ ( $n=471)$ were sure they had not, whereas 15\% $(n=63)$ of technicians/assistants were sure they had, and 58\% $(n=249)$ were sure they had not. The remaining respondents were unsure. A $\chi^{2}$ test showed that the 2 professions did not differ significantly on this variable $\left(\chi^{2}(1, N=1037)=1.15, p=0.28\right)$. Finally, pharmacists were significantly more willing to provide counselling to patients regarding medications used for MAiD (mean 2.6 [SD 1.3]) than to participate in determining eligibility for MAiD (mean 2.9 [SD 1.3]) $(t(606)=7.52, p<0.001)$ (Figure 2).

\section{Eligibility}

Respondents were asked to rate the importance of each eligibility criterion as defined by the government of Canada. ${ }^{19}$ Pharmacists rated the criterion of "clear consent to MAiD" as being significantly more important than did technicians/assistants $(t(766.4)=2.83, p=0.003)$. The 2 groups did not differ significantly on the other criteria. All of the criteria were rated quite highly by both groups, and the groups generally agreed on which criteria were most important. When the 2 groups were combined, lowest importance was given to "age over 18" (mean 3.8 [SD 1.2], median 4 [IQR 2] on 5-point scale) and highest importance to "clear consent" and "no outside pressure" (for both criteria, mean 4.8 [SD 0.7], median 5 [IQR 0] on 5-point scale). Descriptive information for these scores is provided in Table 3.

\section{Knowledge}

Pharmacists (mean 2.7 [SD 1.2] and median 3 [IQR 2] on 5 -point scale, where lower scores indicate more knowledge) reported being more informed of federal legislation regarding MAiD than did technicians/assistants (mean 3.0 [SD 1.2] and median 3 [IQR 2] on 5-point scale) $(t(1038)=3.35, p=0.001)$. Similar results were obtained for knowledge of provincial legislation (for pharmacists, mean 2.7 [SD 1.1], median 3 [IQR 2]; for technicians/assistants, mean 3.0 [SD1.2], median 3 [IQR 2]; $t(1038)=3.1, p=0.002)$. When asked whether they knew of their hospitals' policies regarding MAiD, the majority of both pharmacists (460/595, 77\%) and technicians/assistants (266/423, 63\%) reported working at hospitals that permitted MAiD. A larger percentage of technicians/assistants $(133 / 423,31 \%)$ than pharmacists $(82 / 595,14 \%)$ did not know whether their respective hospitals had a policy regarding $\operatorname{MAiD}\left(\chi^{2}(1, N=1018)=46.29, p<0.001\right)$.

\section{Religious Influence}

Two items on the questionnaire (based on a 7-point scale) addressed religious views. Results indicated that pharmacists (mean 3.1 [SD 2.3] and median 2 [IQR 4]) considered religion to have a stronger influence on their professional work than did technicians/assistants (mean 2.6 [SD 2.2] and median 1 [IQR 3]) $(t(713.8)=2.6, p=0.01)$. However, 15 pharmacists did not answer this question, and a further 107 pharmacists answered "not applicable"; these 122 individuals (20\%) were excluded from the analysis. Similarly, 8 technicians/assistants did not answer this question, and a further 99 technicians/assistants answered "not applicable"; these 107 individuals (25\%) were also excluded from these analyses. Pharmacists (mean 5.0 [SD 2.5] and median 6 [IQR 5]) were more likely than technicians/assistants (mean 4.2 [SD 2.7] and median 4 [IQR 6]) to report that their religious affiliation had negative views regarding MAiD $(t(376.9)=3.19$, $p=0.002)$. For this variable, 23 pharmacists did not answer the question, and a further 288 pharmacists answered "not applicable";

\section{Table 3. Views on Eligibility Criteria for MAiD}

\begin{tabular}{|c|c|c|c|c|}
\hline \multirow[b]{2}{*}{ Criterion } & \multicolumn{2}{|c|}{$\begin{array}{c}\text { Professional Group; \% Rating } \\
\text { Criterion as Moderately or } \\
\text { Very Important }\end{array}$} & \multicolumn{2}{|c|}{$\begin{array}{l}\text { Professional Group; } \\
\text { Mean Score* } \pm \text { SD }\end{array}$} \\
\hline & Pharmacists & $\begin{array}{c}\text { Technicians/ } \\
\text { Assistants }\end{array}$ & Pharmacists & $\begin{array}{c}\text { Technicians/ } \\
\text { Assistants }\end{array}$ \\
\hline Age $\geq 18$ years & 70 & 60 & $3.9 \pm 1.1$ & $3.7 \pm 1.3$ \\
\hline Mental competency & 90 & 86 & $4.6 \pm 0.8$ & $4.5 \pm 0.8$ \\
\hline Grievous medical condition & 90 & 85 & $4.6 \pm 0.8$ & $4.5 \pm 0.9$ \\
\hline Irremediable medical condition & 88 & 84 & $4.5 \pm 0.8$ & $4.4 \pm 1.0$ \\
\hline Intolerable suffering & 90 & 87 & $4.6 \pm 0.8$ & $4.6 \pm 0.9$ \\
\hline Reasonably foreseeable death & 81 & 80 & $4.3 \pm 1.0$ & $4.3 \pm 1.1$ \\
\hline Clear consent to MaiD† & 94 & 90 & $4.8 \pm 0.6$ & $4.7 \pm 0.8$ \\
\hline No outside pressure or influence & 93 & 90 & $4.8 \pm 0.6$ & $4.7 \pm 0.8$ \\
\hline
\end{tabular}

MaiD = medical assistance in dying, SD = standard deviation .

*The scale ranged from 1 (not at all important) to 5 (very important).

tThe 2 groups were significantly different, at $p<0.006$ (Bonferonni correction). 


\begin{abstract}
Table 4. Relationships between Respondent Characteristics (Demographic and Work Variables) and Outcome Variables for Pharmacists, Using Point-Biserial Correlations for Binary Variables and Pearson Correlations for Continuous Variables*
\end{abstract}

\begin{tabular}{|c|c|c|c|c|c|c|c|c|c|}
\hline \multirow[b]{2}{*}{ Characteristic } & \multicolumn{4}{|c|}{ Values } & \multicolumn{3}{|c|}{ Reluctance } & \multirow[b]{2}{*}{$\begin{array}{c}\text { Willing to } \\
\text { Counsel }\end{array}$} & \multirow[b]{2}{*}{$\begin{array}{l}\text { Willing to } \\
\text { Decide } \\
\text { Eligibility }\end{array}$} \\
\hline & $\begin{array}{l}\text { Right to } \\
\text { End Life }\end{array}$ & $\begin{array}{c}\text { Assistance } \\
\text { of Medical } \\
\text { Professionals }\end{array}$ & $\begin{array}{l}\text { Use of } \\
\text { Prescription } \\
\text { Meds }\end{array}$ & $\begin{array}{l}\text { Responsibility } \\
\text { to Refer }\end{array}$ & $\begin{array}{l}\text { Willing to } \\
\text { Participate }\end{array}$ & $\begin{array}{l}\text { Willing to } \\
\text { Dispense }\end{array}$ & $\begin{array}{l}\text { Right to } \\
\text { Refuse }\end{array}$ & & \\
\hline \multicolumn{10}{|l|}{ Respondent characteristics } \\
\hline Age & 0.10 & 0.10 & 0.08 & 0.10 & 0.06 & 0.01 & -0.04 & 0.06 & -0.001 \\
\hline Sext & -0.06 & -0.06 & -0.06 & -0.05 & -0.05 & -0.02 & -0.02 & 0.03 & -0.01 \\
\hline Religious influence $\neq$ & $0.67 * *$ & $0.67 * *$ & $0.63 * *$ & $0.34 * *$ & $0.69 * *$ & $0.66 * *$ & $-0.38 * *$ & $0.55^{* *}$ & $0.42 * *$ \\
\hline Religion and MAiD§ & $0.41 * *$ & $0.42 * *$ & $0.39 * *$ & 0.13 & $0.41 * *$ & $0.40 * *$ & $-0.29 * *$ & $0.30 * *$ & $0.28 * *$ \\
\hline \multicolumn{10}{|l|}{ Professional characteristics } \\
\hline Size of hospital & -0.01 & -0.02 & -0.02 & -0.03 & -0.01 & -0.03 & -0.08 & 0.004 & -0.03 \\
\hline Direct patient care & -0.01 & 0.02 & 0.01 & 0.05 & 0.03 & 0.06 & -0.04 & -0.05 & -0.04 \\
\hline End-stage care & -0.01 & -0.03 & -0.02 & -0.02 & -0.03 & -0.05 & -0.01 & 0.07 & 0.06 \\
\hline Practice areaף & -0.01 & -0.003 & -0.02 & 0.04 & 0.01 & -0.03 & -0.01 & -0.03 & 0.03 \\
\hline \multicolumn{10}{|l|}{ Policy } \\
\hline Knowledge of legislation & $0.10+\dagger$ & $0.12 * *$ & $0.15^{\star \star}$ & $0.13^{* *}$ & $0.19 * *$ & $0.22 * *$ & 0.07 & $0.16^{\star *}$ & $0.15^{* *}$ \\
\hline Hospital policy & -0.04 & -0.05 & -0.03 & -0.06 & -0.02 & 0.02 & 0.08 & -0.09 & -0.11 \\
\hline \multicolumn{10}{|c|}{$\begin{array}{l}\text { MAiD = medical assistance in dying. } \\
\text { *For all outcome variables, higher values indicate opposition to MAiD. Using the Bonferroni correction, the critical } p \text { value for significance } \\
\text { was } 0.005 \text {. Because of missing data, the sample size ranged from } 571 \text { to } 607 \text {, except for religious influence on work }(n=485) \text { and religion } \\
\text { and MAiD ( } n=296) \text {. Participants who chose "not applicable" on the latter } 2 \text { variables were excluded from the analyses. } \\
\text { tMen were coded as } 1 \text { and women as } 2 \text {. } \\
\text { fHigher scores indicate more religious influence on views toward MAiD. } \\
\text { §Higher scores indicate more negativity regarding MAiD by religious affiliation. } \\
\text { १For practice area, working or having worked in palliative care/oncology was coded as } 1 \text {, and never having worked in these areas } \\
\text { was coded as } 0 \text {. }\end{array}$} \\
\hline
\end{tabular}

these 311 individuals (51\%) were excluded from the analysis. Similarly, 16 technicians/assistants did not answer this question, and a further 227 technicians/assistants answered "not applicable"; these 243 individuals (56\%) were also excluded from the analysis.

\section{Predicting Scores}

The relationships between respondent characteristics (demographic and work variables) and outcome variables are shown in Tables 4 and 5, using point-biserial correlations for binary variables and Pearson correlations for continuous variables. The results of these analyses indicated that both pharmacists and technicians/assistants with stronger religious beliefs and those whose religious affiliations reject MAiD were less supportive of MAiD. Generally, professional characteristics were not strong predictors, and individuals who were better informed about provincial and federal legislation were more supportive of MAiD. Finally, technician/assistant respondents who reported working at hospitals that permitted MAiD were also more supportive of MAiD. Given that many respondents reported "not applicable" when asked to rate the importance of religion to their professional work, religiosity was further explored by creating one group of individuals for whom religion was somewhat or very important, and comparing their views on religion to the rest of the sample. The latter group was made up of individuals who chose "not applicable" and those who reported that their religious views did not influence their work regarding MAiD. For both pharmacists and technicians/assistants, the group with a higher level of religiosity had significantly more negative views regarding MAiD $(p<0.001)$ in terms of each of the values and reluctance variables.

For some outcomes, region was also important. When pharmacists in the 4 regions of the country were compared, significant results were obtained for willingness to participate in $\operatorname{MAiD}(F(3,603)=4.30, p=0.005)$, right to refuse $(F(3,603)=5.36, p=001)$, and willingness to provide counselling $(F(3,603)=4.38, p=0.005)$. Post hoc tests indicated that pharmacists in the western part of the country (Alberta, British Columbia, Yukon) were less willing to participate than those in central Canada (Quebec, Ontario) and the Atlantic provinces (New Brunswick, Prince Edward Island, Nova Scotia, Newfoundland and Labrador), were more likely than those in the Prairie provinces (Saskatchewan and Manitoba) to agree that a pharmacist should be able to refuse to dispense MAiD medications, and were less willing than pharmacists in central Canada to provide counselling about MAiD medications.

When technician/assistant respondents from different regions were compared, the only significant result related to the appropriateness of refusing to fill out a prescription for use in $\operatorname{MAiD}(F(3,429)=5.0, p=0.002)$. For this variable, respondents in the western region (Alberta, British Columbia, Yukon) were less supportive of MAiD than those in central Canada (Quebec, Ontario). 


\section{Table 5. Relationships between Respondent Characteristics and Outcome Variables for Pharmacy Technicians and Assistants, Using Point-Biserial Correlations for Binary Variables and Pearson Correlations for Continuous Variables*}

\begin{tabular}{|c|c|c|c|c|c|c|c|}
\hline \multirow[b]{2}{*}{ Characteristic } & \multicolumn{4}{|c|}{ Values } & \multicolumn{3}{|c|}{ Reluctance } \\
\hline & $\begin{array}{l}\text { Right to } \\
\text { End Life }\end{array}$ & $\begin{array}{l}\text { Assistance } \\
\text { of Medical } \\
\text { Professionals }\end{array}$ & $\begin{array}{c}\text { Use of } \\
\text { Prescription } \\
\text { Medications }\end{array}$ & $\begin{array}{l}\text { Responsibility } \\
\text { to Refer }\end{array}$ & $\begin{array}{l}\text { Willing to } \\
\text { Participate }\end{array}$ & $\begin{array}{l}\text { Willing to } \\
\text { Dispense }\end{array}$ & $\begin{array}{l}\text { Right to } \\
\text { Refuse }\end{array}$ \\
\hline \multicolumn{8}{|c|}{ Respondent characteristics } \\
\hline Age & -0.01 & -0.03 & -0.03 & 0.12 & 0.01 & -0.01 & 0.07 \\
\hline Sext & -0.12 & $-0.14 \dagger \dagger$ & -0.13 & -0.09 & -0.09 & -0.13 & 0.03 \\
\hline Religious influenceł & $0.56 * *$ & $0.55^{* *}$ & $0.53 * *$ & $0.21 * *$ & $0.55 * *$ & $0.55^{* *}$ & $-0.25 * *$ \\
\hline Religion and MAiD§ & $0.33^{* *}$ & $0.31 * *$ & $0.29 * *$ & 0.04 & $0.32 * *$ & $0.31 * *$ & -0.17 \\
\hline \multicolumn{8}{|c|}{ Professional characteristics } \\
\hline Size of hospital & -0.06 & -0.06 & -0.03 & -0.02 & -0.04 & -0.06 & $0.13 \neq \ddagger$ \\
\hline Direct patient care & -0.09 & -0.13 & -0.09 & -0.07 & -0.12 & -0.11 & 0.10 \\
\hline End-stage care & 0.06 & 0.11 & 0.09 & 0.09 & 0.08 & 0.08 & -0.10 \\
\hline Practice areaף & -0.10 & -0.10 & -0.08 & -0.08 & -0.04 & -0.04 & 0.08 \\
\hline \multicolumn{8}{|l|}{ Policy } \\
\hline Knowledge of legislation & $0.23 * *$ & $0.24 * *$ & $0.26 * *$ & $0.09 \neq \ddagger$ & $0.21 * *$ & $0.21 * *$ & $0.14 * *$ \\
\hline Hospital policy & $0.16 * *$ & $0.16 * *$ & $0.16 * *$ & 0.08 & $0.18 * *$ & $0.16^{* *}$ & $0.16^{* *}$ \\
\hline
\end{tabular}

MaiD = medical assistance in dying.

*For all outcome variables, higher values indicate opposition to MAiD. Using the Bonferroni correction, the critical $p$ value for significance was 0.005 . Because of missing data, the sample size ranged from 418 to 433 , except for religious influence on work $(n=326)$ and religion and MAiD $(n=190)$. Participants who chose "not applicable" on the latter 2 variables were excluded from the analyses.

tMen were coded as 1 and women as 2 .

¥Higher scores indicate more religious influence on views toward MAiD.

$\S$ Higher scores indicate more negativity regarding MAiD by religious affiliation.

IFor practice area, working or having worked in palliative care/oncology was coded as 1, and never having worked in these areas was coded as 0.

**Correlation was significant using both the Spearman (nonparametric) and the Pearson (parametric) correlations.

†+Correlation was significant using the Pearson (parametric) correlation, but nonsignificant using the Spearman (nonparametric) correlation.

$\ddagger \ddagger$ Correlation was significant using the Spearman (nonparametric) correlation, but nonsignificant using the Pearson (parametric) correlation.

\section{DISCUSSION}

The goals of the study were to investigate the attitudes and self-rated knowledge of hospital pharmacy staff regarding MAiD and to identify predictors of these attitudes, for both pharmacists and pharmacy technicians and assistants. Few published studies have considered the knowledge and attitudes of hospital pharmacy technicians and pharmacy assistants regarding MAiD in Canada. Overall, both pharmacists and pharmacy technicians and assistants working in the hospital setting were very supportive of MAiD, a finding that was also reported by Verweel and others, ${ }^{8}$ who surveyed hospital and community pharmacists and technicians who were members of the Ontario Pharmacists Association. In the present study, respondents rated all MAiD eligibility criteria as very important. Generally, technicians and assistants who responded to this survey were more supportive of MAiD than their pharmacist counterparts. Furthermore, they were more willing to knowingly dispense medications for MAiD. It is difficult to determine why technicians and assistants had a more supportive opinion of MAiD than pharmacists. It is possible that technicians and assistants have less direct contact with patients and families, which thereby affords them a more objective view. However, percentage of time spent in direct patient care was not a significant predictor of values or reluctance. Another possibility is that pharmacists' more extensive knowledge of therapeutic options to manage palliative symptoms lessens the likelihood of considering death as the best option for patients who qualify for MAiD. Although we combined pharmacy technicians and assistants in the present study, education and professional duties differ between these groups, and these factors may affect their views on MAiD and other topics. Researchers may want to explore these potential differences in future studies.

We hypothesized that pharmacy staff with strong religious beliefs would be less supportive of MAiD, as has been found in several previous surveys. ${ }^{711,12,15}$ In the present study, the strongest predictors of attitudes toward MAiD were religious in nature. Interestingly, a large number of the respondents to this survey indicated that their religious beliefs did not affect their professional work related to MAiD, and, on average, these individuals were more supportive of MAiD than pharmacy staff who reported that their religious beliefs influenced their work. 
We also found that pharmacy staff in the western part of the country (Alberta, British Columbia, Yukon) tended to be less supportive of MAiD. This unexpected finding requires replication for confirmation and may merit further research. One possibility is that the training programs in different parts of the country differ in terms of the views about MAiD that are inculcated in students. Pursuing this question would require linking practising pharmacists with their respective programs of study, which was not possible with the present data set. This finding could also reflect differences in the palliative care services available in different regions, which may affect attitudes regarding MAiD. MAiD has been legal in Quebec since 2014, which may partially account for respondents in central Canada (Quebec, Ontario) appearing more willing to be involved in the process than pharmacy staff in the west.

Furthermore, we hypothesized that pharmacy staff who had frequent interactions with terminally ill patients and/or had worked in palliative care or oncology would be more supportive of MAiD, as was demonstrated by the Rupp and Isenhower survey. ${ }^{12}$ This hypothesis was not supported by the results of our survey: pharmacists and technicians/assistants who worked or had worked in palliative care and oncology did not have significantly different opinions from those who worked in other areas. However, only about $10 \%$ of respondents were working in palliative care or oncology/hematology at the time of the survey. This sample may have been too small to allow a significant difference to be found, if such a difference had existed. It would be interesting to pursue this question by carrying out a further survey with this specific population.

A novel finding in the present study was the importance of knowledge about MAiD legislation as a predictor of support for the practice. Similar to the $\mathrm{CPhA}$ survey ${ }^{16}$ and the survey completed by Verweel and others, ${ }^{8}$ the majority of respondents to our survey felt they lacked comprehensive education on the topic. We propose here that formal pharmacy education for both technicians and pharmacists should include MAiD, as it is likely to be encountered at some point in their future careers. At the time of this survey, MAiD had been legal in Canada for only 8 months, yet already one-third of respondents had dispensed a prescription for its use. The results of this survey suggest that the preferred format for education regarding MAiD would be during undergraduate training for pharmacists and through continuing education for pharmacy technicians/assistants. In the present study, people who were more knowledgeable about MAiD legislation were also more supportive of it. However, the directionality of this relationship is not clear: Does support of MAiD lead professionals to read the legislation, or does reading the legislation lead to positive views? The survey also did not address the influence of position statements drafted or published by various pharmacy professional or other health care organizations. To address these questions, it may be interesting to repeat this survey in 5 to 10 years. It is possible that pharmacy staff will become even more supportive of MAiD as they learn more about the process and have more experience with it.

It appears that the future of health care in Canada will include MAiD as one aspect of autonomy for patients who meet the criteria. This study has demonstrated that the majority of pharmacy staff members are willing to be involved in this new practice and to aid in granting these patients their final wish. However, this research (along with 2 other studies ${ }^{8,16}$ ) reveals that pharmacy staff feel they are lacking education on the topic. Additionally, it appears that as people become more educated on the topic, their support increases.

\section{Strengths and Limitations}

This study had several strengths, including its large sample size encompassing pharmacy staff across Canada. This study was also one of the first to survey hospital pharmacy technicians and assistants on this timely and important topic. Unfortunately, it was impossible to reach all hospital pharmacy staff in Canada because of various anti-spam regulations; therefore, the regions of the country may not all have been represented to the same extent. Additionally, some sampling bias is possible, given that this topic has generated much discussion in workplaces and in society at large, and those with a strong opinion on the subject may have been more likely to respond. In future research projects on this topic, a mixed-methods approach may be helpful to gain a better understanding of the motivation and thoughts behind various responses. Such an approach would also allow an exploration of how attitudes regarding MAiD are influenced by past experiences such as the death of a loved one or particularly harrowing experiences with dying patients.

\section{CONCLUSION}

Overall, pharmacy staff across the country who responded to this survey tended to be very supportive of MAiD. Moreover, technicians and assistants who responded to this survey tended to be more supportive of MAiD than pharmacists, including attitudes regarding MAiD and willingness to carry out professional duties related to MAiD. The strongest predictors of supportive attitudes toward MAiD included respondents' knowledge of federal and provincial legislation, as well as the combination of degree of religious faith and the stance of one's faith on MAiD. In conclusion, these findings highlight the importance of education in preparing pharmacy staff to carry out a scope of practice that increasingly includes MAiD across the country.

\footnotetext{
References

1. Carter v. Canada (Attorney General), 2015 SCC 5 [2015] 1 S.C.R. 331 [cited 2018 Jun 26]. Available from: http://scc-csc.lexum.com/scc-csc/ scc-csc/en/item/14637/index.do

2. Hurst SA, Mauron A. Assisted suicide and euthanasia in Switzerland: allowing a role for non-physicians. BMJ. 2003;326(7383):271-3.
} 
This single copy is for your personal, non-commercial use only.

For permission to reprint multiple copies or to order presentation-ready copies for distribution, contact CJHP at publications@cshp.ca

3. Emanuel EJ, Onwuteaka-Philipsen BD, Urwin JW, Cohen J. Attitudes and practices of euthanasia and physician-assisted suicide in the United States, Canada, and Europe. JAMA. 2016;316(1):79-90.

4. Emanuel EJ. Euthanasia: historical, ethical, and empiric perspectives. Arch Intern Med. 1994;154(17):1890-901.

5. Bill 52: An act respecting end-of-life care. Quebec National Assembly; [assented to 2014 Jun 10; cited 2018 Jun 26]. Available from: http://www2.publicationsduquebec.gouv.qc.ca/dynamicSearch/telecharge. php?type $=5 \&$ file $=2014 \mathrm{C} 2 \mathrm{~A} \cdot \mathrm{PDF}$

6. Rupp MT. Physician-assisted suicide and the issues it raises for pharmacists. Am J Health Syst Pharm. 1995;52(13):1455-60.

7. Hanlon TR, Weiss MC, Rees J. British community pharmacists' views of physician-assisted suicide (PAS). J Med Ethics. 2000;26(5):363-9.

8. Verweel L, Rosenberg-Yunger ZRS, Movahedi T, Malek AH. Medical assistance in dying: examining Canadian pharmacy perspectives using a mixed methods approach. Can Pharm J (Ott). 2018;151(2):121-32.

9. Frequently asked questions for dispensers: dispensing publicly funded kits for medical assistance in dying (MAID) and claims submission using the health network system. Toronto (ON): Ministry of Health and Long-Term Care, Ontario Public Drug Programs Division; [updated 2016 Aug 10; cited 2018 Jun 25]. Available from: www.health.gov.on.ca/en/pro/programs/drugs/ opdp_eo/notices/fq_exec_office_20160815.pdf

10. Schneiderhan ME. Physician-assisted suicide and euthanasia: the pharmacist's perspective. Omega. 1999-2000;40(1):89-99.

11. Hackett EA, Francis SA. "Death was a blessing"-should it ever be pharmaceutically hastened? British pharmacists' views. Pharm World Sci. 2003;25(6):288-93.

12. Rupp MT, Isenhower HL. Pharmacists' attitudes toward physician-assisted suicide. Am J Hosp Pharm. 1994;51(1):69-74.

13. Vivan JC, Slaughter RL, Calissi P. Michigan pharmacists' attitudes about medically-assisted suicide. J Mich Pharm. 1993;31:490-5.

14. Bilsen J, Bauwens M, Bernheim J, Stichele RV, Deliens L. Physician-assisted death: attitudes and practices of community pharmacists in East Flanders, Belgium. Palliat Med. 2005;19(2):151-7.

15. Lau HS, Riezebos J, Abas V, Porsius AJ, De Boer A. A nation-wide study on the practice of euthanasia and physician-assisted suicide in community and hospital pharmacies in The Netherlands. Pharm World Sci. 2000;22(1):3-9.

16. Submission to the external panel on options for a legislative response to Carter v. Canada. Ottawa (ON): Canadian Pharmacists Association; 2015 [cited 2018 Jun 26]. Available from: https:/www.pharmacists.ca/cpha-ca/ assets/File/cpha-on-the-issues/CPhA\%20Submission\%20to\%20the\%20 External\%20Panel\%20on\%20Legislative\%20Options\%20for\%20 Assisted\%20Dying.pdf

17. Murphy AL, O'Reilly C, Martin-Misener R, Ataya R, Gardner D. Community pharmacists' attitudes on suicide: A preliminary analysis with implications for medical assistance in dying. Can Pharm J (Ott). 2018; 151(1):17-23
18. Mitchell F, Gould O, LeBlanc M, Manuel, L. Opinions of hospital pharmacists in Canada regarding marijuana for medical purposes. Can J Hosp Pharm. 2016;69(2):122-30.

19. Eligibility criteria. In: Medical assistance in dying [webpage]. Ottawa (ON): Government of Canada; [cited 2018 Jun 26]. Available from: https:// www.canada.ca/en/health-canada/services/medical-assistance-dying. html\#a2

20. National statistics. Ottawa (ON): National Association of Pharmacy Regulatory Authorities; 2018 [cited 2018 Jun 29]. Available from: http://napra.ca/national-statistics

Adrienne Gallagher, BSc(Bio/Psych), BSc(Pharm), ACPR, was, at the time of this study, a Pharmacy Resident at Horizon Health Network, Moncton, New Brunswick. She is now a pharmacist with the Nova Scotia Health Authority, Sydney, Nova Scotia.

Odette Gould, PhD, is a full professor in the Department of Psychology, Mount Allison University, Sackville, New Brunswick, and an Adjunct Research Scientist with Horizon Health Network.

Michael LeBlanc, BSc(Chem), BSc(Pharm), PharmD, FCSHP, is Clinical Pharmacy Manager and Clinical Pharmacy Specialist, Oncology with Horizon Health Network, Moncton, New Brunswick.

Leslie Manuel, BSC(Pharm), ACPR, PharmD, is Clinical Pharmacy Manager and Clinical Pharmacy Specialist, Emergency Medicine with Horizon Health Network, Moncton, New Brunswick.

Diane Brideau-Laughlin, BSc(Pharm), MSc(HTA), FCSHP, was, at the time of this study, Clinical Pharmacy Specialist, Oncology and Palliative Care with Horizon Health Network, Moncton, New Brunswick. She has since retired.

Competing interests: None declared.

\section{Address correspondence to:}

Adrienne Gallagher

Cape Breton Regional Hospital

1482 George Street

Sydney NS B1P 1P3

e-mail: adrienne.gallagher@nshealth.ca

Funding: None received. 